\title{
Difficult ERCP with Aberrant Papilla A Report of Three Cases
}

\author{
S PERVEEN ${ }^{\mathrm{a}}, \mathrm{SMM} \mathrm{RAHMAN}^{\mathrm{b}}$, MSMM HOSSAIN $^{\mathrm{c}}, \mathrm{NG}^{\mathrm{N}} \mathrm{CHOWDHURY}^{\mathrm{d}}$, MA AHMED $^{\mathrm{e}}$
}

\section{Summary:}

The ampulla of Vater encompasses the openings of both the common bile duct (CBD) and pancreatic duct (PD). Presently ERCP has allowed better observation of the papillae in ectopic locations. The diagnosis of ectopic papillae can be done by radiological studies also but they are expensive and not affordable by all patients so most of the cases of ectopic papillae are identified by ERCP. An ectopic location, distal to the second part, in the third or fourth parts of duodenum has been described frequently but a proximal location is rare. Only a few cases have been found to be located in the gastric, pyloric and duodenal bulb areas. We report three such rare cases of anomalous ectopic ampullae discovered during the performance of

\section{Introduction:}

The ampulla of Vater is ideally located in the posteromedial wall of the second part of the duodenum. The common bile duct (CBD) normally goes through an oblique, 1-2 cm long intramural part and then opens within the wall of the duodenum surrounded by the small circular and longitudinal muscular segments that comprise the sphincter of Oddi. At times, the ampulla of Vater may be anomalous in ectopic locations and in uncommon sites such as the third and fourth portions of the duodenum, the duodenal bulb and the stomach. It has hardly ever been found at the pylorus ${ }^{[1]}$. An ectopic location of the ampulla distal to the second part has been described frequently but in a proximal

a. Col Shaila Perveen, MCPS, FCPS(Med),FRCP(Glasg), Classified Medicine Spl \& Senior Gastroenterologist CMH, Dhaka.

b. Lt Col SM Mizanur Rahman,FCPS(Med),FCPS(Gastro), Classified Medicine Spl \& Gastroenterologist CMH,Dhaka

c. Maj Gen Md S M Motahar Hossain MCPS,FCPS(Med), Director General Medical Services,Bangladesh Armed Forces

d. Col Niamul Gani Chowdhury, FCPS(Med), Personal Physician to Honorable President \& Gastroenterologist,Dhaka

e. Col Mir Azimuddin Ahmed, DCP,MCPS, FCPS(Hemato), Professor \& Classified Spl in Hematology AFMC, Dhaka

Address for Correspondence: Colonel Shaila Perveen, Classified Medicine Spl \& Senior, Gastroenterologist CMH, Dhaka. Mob: +88 01819294922, +88 01769014578, E-mail: majshaila@yahoo.com

Received: 7 June 2017

Accepted: 27 Dec. 2017
ERCP from the Department of Gastroenterology, Combined Military Hospital, Dhaka and also a short review of the literature. In these three subjects one papilla was located in the pylorus and other two in the first part of the duodenum. All of them presented with features of choledocholithiasis with cholangitis. They were successfully managed by therapeutic ERCP. Clinical implications of these rare anomalies and anatomical variations can assist the gastroenterologists in effective patient management.

Key words: Common bile duct, Pancreatic duct, Ectopic biliary drainage, Endoscopic retrograde cholangiopancreatography, Ampulla of Vater.

(J Bangladesh Coll Phys Surg 2018; 36: 37-40)

location is rare. In three subjects one papilla was located in the pylorus, one in a normal duodenal bulb and another one in the first part of duodenum within two large duodenal diverticuli. All these patients were successfully managed by some modification of therapeutic ERCP procedure. So awareness of such rare conditions can assist the gastroenterologists in effective patient management.

\section{Case Report:}

Three male patients of forty four, fifty eight and eighty two years of age presented with fever and jaundice with abdominal pain and altered liver enzymes. All of them had recurrent cholangitis, elevated Alkaline phosphatase and one had raised CA 19-9. Their total bilirubin ranged from 4.6 to $9.4 \mathrm{mg} / \mathrm{dl}$, C-reactive protein level was 30 to $190 \mathrm{mg} / \mathrm{dL}$, alanine-aminotransferase 44 to $95 \mathrm{IU} / \mathrm{L}$, leucocytes 15,500 to $18,400 / \mathrm{mm}^{3}$ and Abdominal ultrasonography showed dilatation of the extrahepatic bile duct with stones, a feature of choledocholithiasis in all three and cholelithiasis in one. History of cholecystectomy was present in 2 of the cases and duodenal ulcer in one. After the diagnosis of obstructive jaundice with dilatation of the bile ducts, ERCP was performed.

During ERCP, in case 1 no area suggesting the presence of the papilla of Vater was found within the second part of duodenum or lower down. Front view endoscope was 
employed to search for the papillary opening. Finally, the papilla was found to be located in the anatomical pyloric channel (Fig I). Cholangiogram was also done with endoscope due to technical difficulty in using duodenoscope. It showed dilated CBD with filling defect (Fig 2). In two other cases during ERCP, being unable to find the papilla down we searched up and found them in duodenal bulb. In case 2 it was in normal bulb while in case 3 it was in between two large duodenal diverticulae (Fig 3) with a separately identifyable pancreatic opening (Fig 4). Controlled Release Expansion (CRE) balloon dilatation of the CBD rather

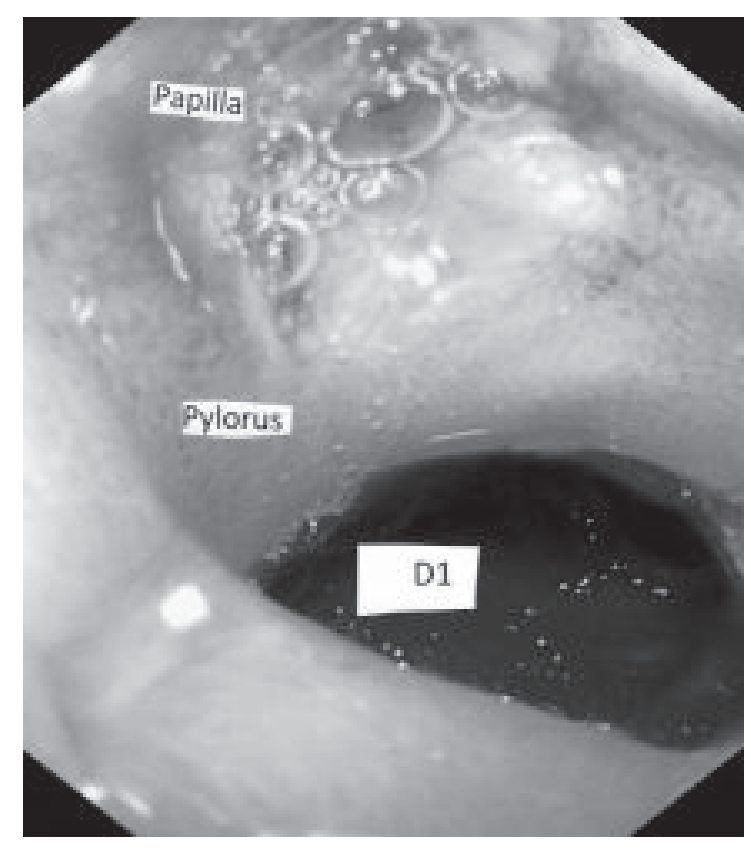

Fig.-1: Ectopic location of papilla at pylorus

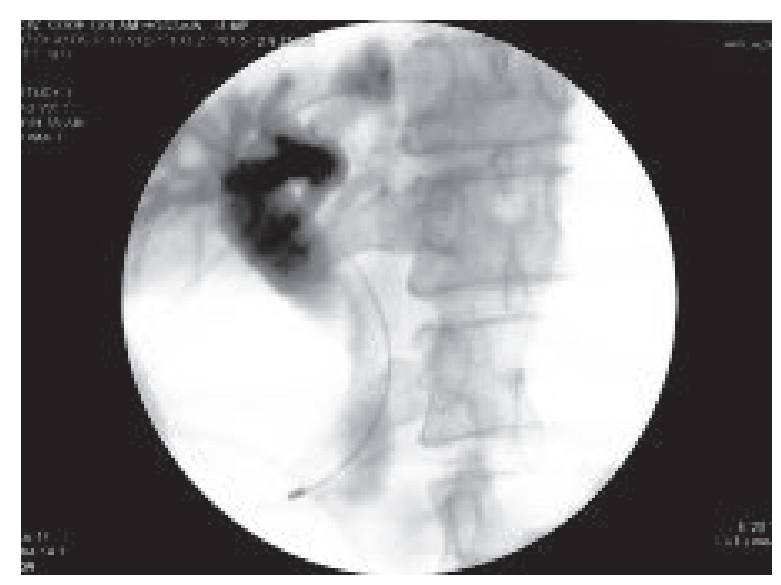

Fig.-2: Cholangiogram done with Endoscope than papillotomy was chosen for therapeutic technique (Fig 5) in these cases as in the literature. Alteration in anatomy and diverticuli increased technical difficulty and risk of perforation during papillotomy with a theoretically higher risk of other complications. After dilatation of the papilla with a CRE (controlled release expansion) balloon (Fig 6) and removal of stones using extraction balloon and Dormia basket, the free flow of bile was established (Fig 7) which solved the problem of obstructive jaundice. In the first case, a single large stone was retrieved by balloon sweeping and in the other cases multiple stones were cleared by Dormia basket without further complications.

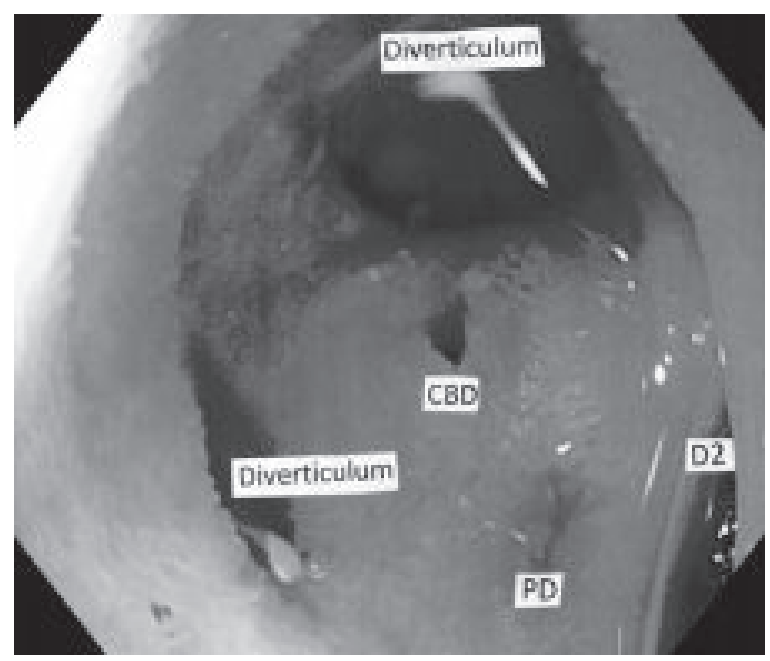

Fig.-3: $C B D$ and PD amidst two Duodenal Diverticulae

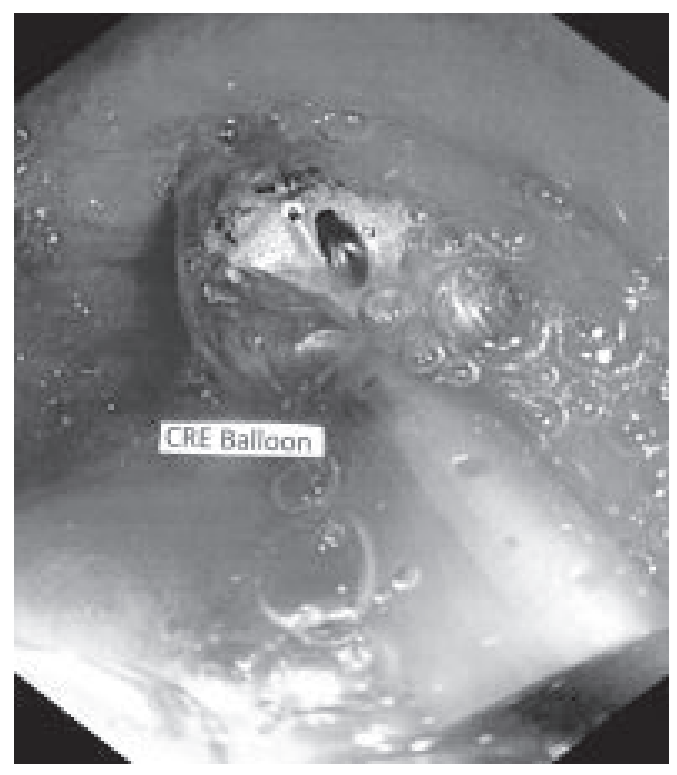

Fig.-4: $C R E$ Balloon in $C B D$ 


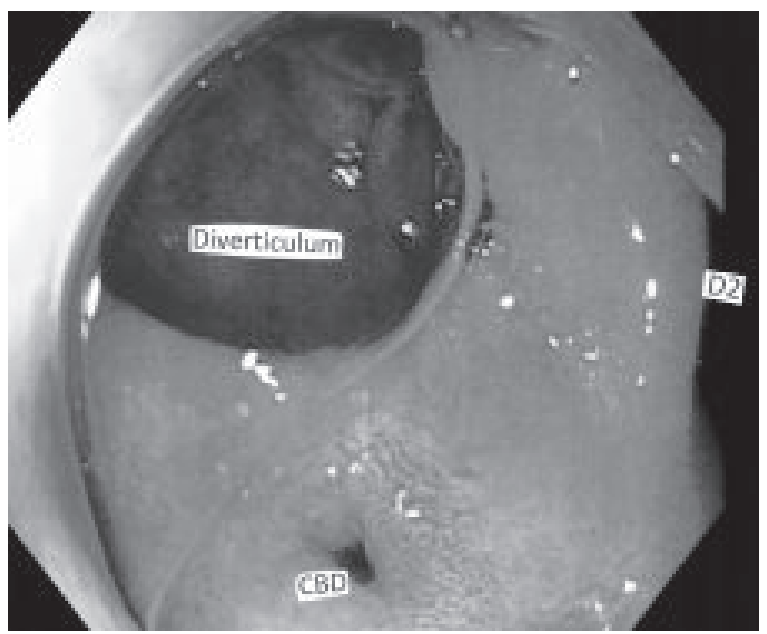

Fig.-5: $C B D$ Before CRE Balloon dilatation at ERCP

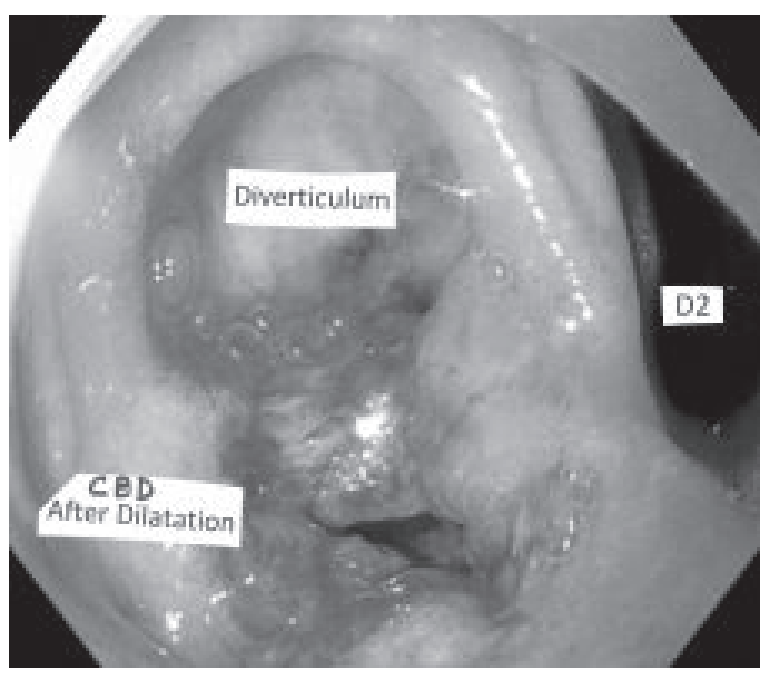

Fig.-6: $C B D$ after $C R E$ balloon dilatation

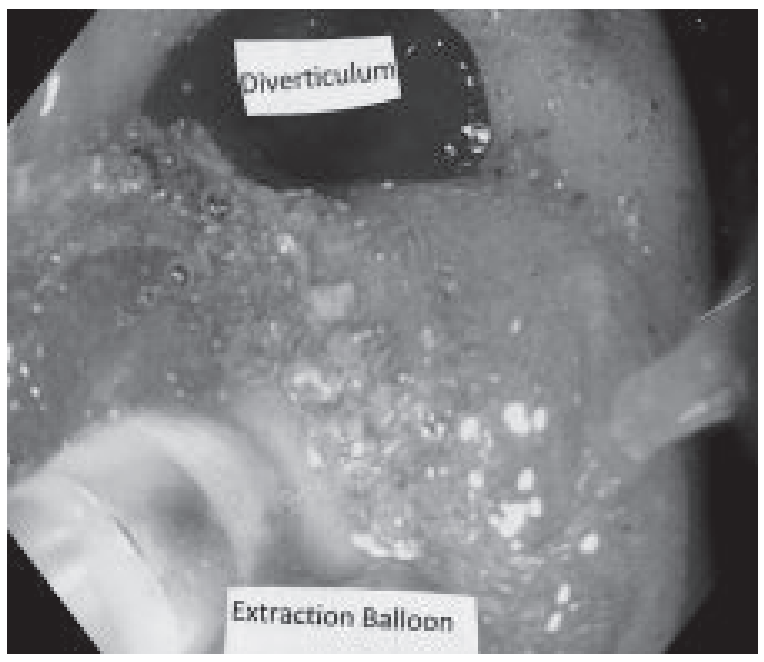

Fig.-7: Free flow of bile with stone extraction
In these three subjects one papilla was located in the pylorus, one in the first part of duodenum within two large duodenal diverticuli and another one in a normal duodenal bulb. Normal formation of papilla were absent in these patients and a slit-like opening was found instead. Pancreatic duct (PD) was opening separately in one case where it was possible to visualize. All presented with fever and jaundice with right upper abdominal pain and altered liver enzymes. Ultrasound showed dilated common bile duct with stone. A feature of choledocholithiasis with cholangitis. All these patients were successfully managed by some modification of therapeutic ERCP procedure.

\section{Discussion:}

The origin of ectopic papillae has usually been suggested during embryonic life.The liver originates in the hepatic diverticulum which is divided into the hepatic pars and the cystic pars during embryogenesis. The hepatic pars then develops into both the liver and the hepatic ducts while the cystic pars develops into the gall-bladder and the cystic duct. The common bile duct originates in the hepatic antrum, which is the common area of the hepatic diverticulum. Earlier subdivision of the hepatic diverticulum could cause the common bile duct to empty into different locations other than the usual location ${ }^{2}$.

Ectopic papillae located in the duodenal bulb may be secondary to a duodenal pathology like ulcer and scarring leading to anomalous drainage in the duodenum. The location of the papilla in our patient beside diverticuli might be related to such duodenal ulcer followed by development of diverticulae formation. In these cases we could not find signs of the papilla in the second duodenal portion or distally. Papilla in the pyloric channel and the duodenum might be related to a congenital malformation with anomalous biliary and pancreatic drainage.In our subjects we observed the diagnostic requirements for an ectopic papilla as described by Lee $\mathrm{et}^{\mathrm{a}} \mathrm{l}^{3}$. Criteria for an ectopic location of papilla were:

(1) An orifice observed in the bulb by duodenoscopy and upper endoscopy and the bile duct and/or the pancreatic duct directly visualized radiographically when contrast was injected through this opening.

(2) There was direct drainage of the common bile duct into the duodenal bulb without evidence of any other drainage into the duodenum on cholangiography and 
(3) There was no evidence of a papilla-like structure in the second or third portion on duodenoscopic examination.

Fistula secondary to peptic ulcer disease or choledocholithiasis, spontaneous or iatrogenic surgical fistula and surgical choledochoenteric diversion should be excluded.

The clinical importance of ectopic location of the papilla is due to the fact that due to the lack of a sphincter mechanism there is a tendency for the development of choledocholithiasis through anomalous bile drainage. It can lead to mucosal damage in the area with swelling and ulcer formation due to the action of biliary and pancreatic secretions.

The absence of a sphincter allows passage of the gastroduodenal contents into the common bile duct causing cholangitis in association with biliary obstruction $^{4}$. A case has been described where the papilla was located in the posterior duodenal wall below the pylorus presenting as recurrent upper GI bleeding ${ }^{5}$. In a recent study by Disibeyaz et al on 39 patients where the papilla was located in the bulb recorded episodic abdominal pain in $95 \%$ of patients and cholangitis in $59 \%$ of patients. Recurrent abdominal pain explain a high percentage of patients undergoing cholecystectomy ${ }^{6}$. The predominance of male sex and an association with ulcerous duodenal pathology in $61.5 \%$ of the patients were emphasized. An ectopic location distal to the second duodenal portion within the third and fourth duodenal portion had a frequency rate of $5.6 \%$ to $23 \%{ }^{[6]}$. Technical difficulty and a higher probability of perforation due to the lack of anatomical reference during a papillotomy makes its use inadvisable and balloon dilatation is the preferred therapeutic technique ${ }^{7}$. Normal formation of papilla were absent in these patients and a slit-like opening found instead. Pancreatic duct (PD) was opening separately in one case where it was possible to visualize. All these patients were successfully managed by therapeutic ERCP. So in difficult ERCP where the papilla cannot be found in its usual location ectopic biliary drainage and abnormal situation of papilla must be considered and searched. The frequency of ectopic biliary drainage by ERCP is $2 \%(10 \text { out of } 400 \text { ERCP })^{8}$.

\section{Conclusion:}

Ectopic location of the papilla though a rare finding, frequent use of ERCP, MRCP, endoscopy and surgical procedures may increase the number of cases diagnosed.
With these case reports, we intended to remind that ectopic biliary drainage must be considered in the differential diagnosis before postponing or declaring failure when the clinician faces difficulty in finding the papilla during ERCP. Cases of peptic ulcer disease or gastric outlet obstruction due to peptic ulcer accompanied by cholangitis or cholestasis should raise the suspicion of an ectopic papilla.

Although a distal location is found most frequently, a proximal location must be taken into account in whom the papilla cannot be found in its usual location. Technical difficulty and a higher probability of perforation due to the lack of anatomical reference during a papillotomy makes its use inadvisable. Balloon dilatation was the chosen therapeutic technique in our cases due to its low rate of complications.

\section{Acknowledgement:}

The authors like to thank Sainik Anisur Rahman and Corporal Jamal Uddin, ERCP technician, CMH Dhaka for their technical support during performance and documentation of the procedures.

\section{References:}

1. S Nasseri-Moghaddam, H Nokhbeh-Zaeem, Z Soroush, S Bani-Solaiman Sheybani et al. Ectopic Location of the Ampulla of Vater Within The Pyloric Channel.Middle East J Dig Dis. 2011; Mar 3(1): 56-58.

2. Shivi Goel, Shaifaly Madan Rustagi, Susmita Saha, Vandana Mehta,Rajesh Kumar Suri et al. Aberrant pancreatic ductal organisation: a case report. Surgical and Radiologic anatomy July 2015; 37(5): 543-46.

3. Lee SS, Kim MH, Lee SK, Kim KP, Kim HJ, Bae JS, et al. Ectopic opening of the common bile duct in the duodenal bulb: clinical implications. Gastrointest Endosc. 2003;57:679-82.

4. Song MH, Jun DW, Kim SH, Lee HH, Jo YJ, Park YS. Recurrent duodenal ulcer and cholangitis associated with ectopic opening of bile duct in the duodenal bulb. Gastrointest Endosc. 2007; Feb 65(2):324-325.

5. Sung HY, Kim JI, Park YB, Cheung DY, Cho SH, Park SH, Han JY, Kim JK.The papilla of Vater just below the pylorus presenting as recurrent duodenal ulcer bleeding.Intern Med. 2007; 46(22):1853-6.

6. Disibeyaz S, Parlak E, Cicek B, Cengiz C, Kuran SO, Oguz D, Güzel H, Sahin B Anomalous opening of the common bile duct into the duodenal bulb: endoscopic treatment. BMC Gastroenterol. 2007;Jul 5 7():26.

7. Iván Guerra, Luis Ramón Rábago, Fernando Bermejo, Elvira Quintanilla and Silvia García-Garzón. Ectopic papilla of Vater in the pylorus. World J Gastroenterol. 2009; Nov 15(41): 52215223. Published online 2009 Nov.

8. Saritas U, Senol A, Ustundag Y. The clinical presentations of ectopic biliary drainage into duodenal bulbus and stomach with a thorough review of the current literature. BMC Gastroenterol. 2010;10:2-8. 